\title{
Correspondence
}

\section{Guidance on the introduction of supervision registers}

Sir: Following the issuing by the NHS Management Executive of the substantive guidance document on the introduction of supervision registers, I have received several letters of concern from members and fellows of the College across the country in relation to the proposals. In addition, strong concerns were voiced at the recent meeting of the College's Council.

I have therefore written to the Secretary of State for Health, stating that while the College supports the introduction of a mechanism to document a small group of patients who require close supervision and care, there is a very strong view that the current proposals are unlikely to succeed in achieving this end.

Concerns highlighted in my letter covered the broad nature of the criterla for inclusion on the register, the resource implications, the medicolegal implications associated with a decision not to include a patient, the legal position facing clinicians in the event of a violent act or suicide committed by a patient who was not included on the register, potential effects on the doctor/ patient relationship, and anxieties in relation to civil liberties and confidentiality.

This letter will be published in the July issue of the Bulletin. In the meantime, copies are available on request from the College Secretary.

F. CALDICOTT, President, Royal College of Psychiatrists

\section{The NHS and Community Care Act, 1990}

Sir: The article by Graham Thornicroft concerning 'recent Government policy and legislation' (Psychiatric Bulletin, January 1994, 18, 13-17) is a useful outline of the arrangements and problems that have developed. However, the author has not perhaps appreciated the full extent of the difficulties that many of us face in implementing aspects of this Act.

For example, he did not stress enough the problems of high dependency hostels in the inner city. Not only are there extensive needs, needs that will be left further unresourced by the move of funds away from some districts, but the qualifications of the staff required to deal with these needs remain poorly analysed. Thus views as to the nature of 'mental illness', which is often termed 'mental distress' by non-health workers, vary significantly. Some social workers operating in hostels see behaviour differently from trained nurses, and may find it intolerable even though it derives from significant psychotic illness. The acknowledged overlap of social and health care, as Dr Thornicroft has outlined, extends further into a confusion of different philosophies that hinder communication. Perversely, the more hostel places there are, the more acute beds are required as respite care, not least because of the terms of the Mental Health Act.

Furthermore, the Act creates no incentive for discharge. Patients on an acute ward, whose essential needs are appropriate housing and supportive care, are much less of a burden to social services when they stay in hospital. When they leave hospital they have to be looked after and paid for. Delays accrue around obtaining community grants, providing reports and going through assessments, creating frustration for patients and distrust between agencies.

Perhaps the most important factor is the sheer bureaucracy involved in the various terminologies used by $\mathrm{Dr}$ Thornicroft. Terms such as 'joint planning', 'brokerage', 'monitoring', 'evaluation', and 'care/case management', all involve lots of people, numerous meetings, and a growing army of administrators. This can lead to easy evasion of direct responsibility, which is the major problem of implementing community care. This is symptomatic of new NHS structures.

Although some of us directly begged Griffiths to unify services, I suspect that the current fragmentation of responsibility nicely shields the Department of Health from the appropriate criticisms of under-resourcing. The unified management of the asylums, without their walled isolation, is still the key requirement.

T.H. TURNER, St Bartholomew's \& Hackney Hospitals, London

\section{Shortage of beds}

Sir: While there has been a continuous shortage of beds in every hospital I have worked in since starting my career in psychiatry in 1991, in the past six months the situation seems to have become markedly worse. This sudden deterioration has been precipitated by increased reluctance to discharge patients from psychiatric beds. In the wake of more stringent government 